\title{
nature
}

\section{Greece should}

\section{abandon a short-sighted policy}

The Greek government's research funding originated in an era of support from the European Union that is coming to an end. The country's potential deserves a much greater focus on fundamental research.

$\mathrm{F}$ ollowing the example set by the United States, nearly all nations of the European Union (EU) now accept that a sensible investment in basic research is required for the national economic good. Greek politicians, on the other hand, remain unshakeably convinced of the opposite. If they have their way, as from this year there will be no single source of money for research that does not require an industrial partner. Greece is poor, they argue, and cannot afford the luxury of funding research for pleasure rather than business.

A battle is raging between the General Secretariat of Research and Technology (GSRT), a department of the Greek Ministry of Development, and the 500 or so tenured researchers who work in its 44 institutes. The researchers argue that the government's approach is shortsighted, and warn that forcing academics to forge artificial partnerships with the still-embryonic Greek industry, which generally has no interest in research, will result in money simply being misspent.

They are right to be incensed. Last year the GSRT research institutes were evaluated by international panels of experts which concluded that some scattered research excellence can be identified. But this is despite, not because of, government policies, which keep salaries uncompetitively low, provide insufficient money to keep institutes in good repair and stocked with basic instrumentation, and, most importantly, provide no source of competitive national research funds.

The best researchers have survived on EU Framework programme grants and other external sources of money, and on EU structural funds which Greece, as one of the poorer EU countries, receives to build up its economic base. But there will almost certainly be no grants available in the next Framework programme, which starts in 2005, at a time when structural funds will also end. The next programme will probably concentrate its research money in large centres of excellence.

A handful of GSRT institutes could compete for such funding, but the lifeblood for the strong research groups in others will be cut off. And the government is making no contingency plans. On the contrary, it has proposed adding a requirement for an industrial partner to qualify for the only source of basic research project money, which exists courtesy of structural funds. And it is in the process of amending its law on research institutes to bring them closer to government policy.

In no other EU country are research and industrial policy so tightly coupled, and so misconceived, as in Greece. The past decade's attempts to force researchers to kick-start the Greek economy have had no obvious effect on its industry's research and development activities. Intensifying the concentration of money spent on forcing this issue is wrong. The money would be better spent investing in basic research, which will deliver when it has industry to deliver to: when the Greek economy has found its feet by other means. Moreover, Greece's total expenditure on research is, at $0.5 \%$ of its gross domestic product (GDP), by far the lowest in the European Union lower even than that of several former communist countries, such as Poland $(0.76 \%$ GDP $)$ and Hungary $(0.73 \%)$, which can by no means be described as 'richer' than Greece.

As external funds dwindle, Greece must prioritize increasing its research expenditure, and create a national research policy that includes a system of competitive funds for basic research. Its government cannot claim that it cannot afford to do so, for it self-evidently cannot afford not to.

\section{Post-genomic cultures}

\section{Like it or not, big biology is here to stay.}

$\mathrm{F}$ rom anatomy to physiology to molecular biology, biological research has for decades been on an ascending slope of increasing systems complexity. The availability of genome sequences heralds a sharp acceleration in the upturn of that slope. Today biology is dominated by small, investigator-driven groups of 'wet' biologists. But techniques looking at the integrated functioning of hundreds to thousands of genes and proteins - such as microarray and other 'whole genome' analyses - inevitably raise the question of whether the study of one or a few genes or proteins is sophisticated enough, given the need to understand cells, pathways and whole organisms.

Wet biology will continue to be essential, but deep understanding of biological processes will also require a more quantitative molecular biology, with a firm grounding in the behaviour of complex networks. A shift towards an information-oriented systems view of biology, which grasps both mathematically and biologically the many elements of a system, and the relationships among them that allow the construction of an organism, is under way.
But the social change required to make this shift painlessly should not be underestimated. Research groups and institutions will need to take bold steps to embrace computational biology and high-throughput technologies, and to move the emphasis from investigator-driven grant proposals to supporting large multidisciplinary teams that extend beyond departmental and institutional boundaries.

These issues have been considered by some, for example by the National Institutes of Health's new Biomedical Information Science and Technology Initiative (http://grants.nih.gov/grants/bistic/bistic. $\mathrm{cfm}$ ). The Bio-X Program at Stanford University is also one of several new flagship interdisciplinary programmes tackling this 'bigger picture of biology'. But one cannot help feeling that the message has yet to reach the bulk of the troops and, moreover, that few of the generals are providing the leadership for them to attack these new fronts confidently. "What does the human genome sequence mean for me, my research and my institution?" is a question all biologists should be asking themselves. 